\title{
Experimental Stark widths and shifts of triply ionized sulfur spectral lines
}

\author{
S. Djeniže $\mathrm{e}^{1,2,3}$, A. Srećković ${ }^{1,2}$, M. Jelisavčić ${ }^{1}$, and S. Bukvić ${ }^{1,2}$ \\ 1 Faculty of Physics, University of Belgrade, 11001 Belgrade, PO Box 368, Serbia, Yugoslavia \\ 2 Isaac Newton Institute of Chile, Yugoslavia Branch, Belgrade, Yugoslavia \\ ${ }^{3}$ Hungarian Academy of Sciences, Budapest, Hungary
}

Received 11 February 2002 / Accepted 30 April 2002

\begin{abstract}
Stark widths and shifts of two prominent triply ionized sulfur (S IV) ultraviolet spectral lines $(309.727 \mathrm{~nm}$ and $311.761 \mathrm{~nm})$ in the $4 \mathrm{~s}^{2} \mathrm{~S}-4 \mathrm{p}^{2} \mathrm{P}^{0}$ transition have been measured in a linear, low-pressure, pulsed arc discharge created in a $\mathrm{SF}_{6}$ plasma at $33600 \mathrm{~K}$ electron temperature and at $2.8 \times 10^{23} \mathrm{~m}^{-3}$ electron density. Presented Stark shifts are the first measurement of the line shift in the S IV spectrum. Obtained broadening parameters have been compared to the available experimental and theoretical data. The transition probability ratio of the mentioned S IV spectral lines is also obtained.
\end{abstract}

Key words. lines: profiles - atomic data

\section{Introduction}

The ionized sulfur spectral lines play an important role in astrophysics. Recently, S III and S IV spectral lines have been obtained in spectra of galaxies with Compact H II Regions (Martin-Hernández et al. 2002). Also, triply ionized sulfur (S IV) spectral lines have been observed in the spectra of the Massive Star Forming Region W51 IRS 2 (Okamoto et al. 2001). S IV emission has been detected, also, in the spectra of the Stellar winds of Supergiants in the Magellanic Clouds (Fullerton et al. 2000; Bianchi et al. 2000). Moreover, S IV UV lines have been observed superimposed on a continuum in a variable EX Hydrae (Mauche 1999).

Therefore, the knowledge of the characteristics of the S IV spectral lines is of interest. If the Stark broadening is the principal pressure-broadening mechanism in plasmas, it is possible to obtain the other plasma parameters essential in the modelling of various plasma compositions and kinetic processes (Lesage 1994; Zeippen 1995) on the basis of the Stark width and shift values. However, only one paper deals with measurements of the Stark widths of two $(309.727 \mathrm{~nm}$ and $311.761 \mathrm{~nm})$ triply ionized sulfur spectral lines (Platiša et al. 1979). Their calculated Stark width values were presented in three papers (Dimitrijević \& Konjević 1981; Hey \& Breger 1980 and Dimitrijević et al. 1996). No experimental Stark shift investigations exist up to now, and only one work (Dimitrijević et al. 1996)

Send offprint requests to: S. Djeniže,

e-mail: steva@ff.bg.ac.yu deals with the theoretical calculations of the S IV Stark shifts, to the knowledge of the authors (Lesage \& Fuhr 1999). The aim of this paper is to present, for the first time, the measured Stark shift $(d)$ values of two prominent S IV spectral lines belonging to the $4 \mathrm{~s}^{2} \mathrm{~S}-4 \mathrm{p}^{2} \mathrm{P}^{0}$ transition with committant Stark FWHM (full-width at half intensity maximum, $W$ ) values at $33600 \mathrm{~K}$ electron temperature $(T)$ and $2.8 \times 10^{23} \mathrm{~m}^{-3}$ electron density $(N)$. Our measured $W$ and $d$ data have been compared to the available theoretical predictions based on various approximations presented by Dimitrijević \& Konjević (1981), Hey \& Breger (1980) and Dimitrijević et al. (1996). Besides, on the basis of the measured relative line intensity ratio we have obtained the ratio of the spontaneous emission probabilities $(A)$ which agree well with existing theoretical predictions (NIST 2002).

\section{Experiment}

The linear pulsed arc, used as the plasma source, was described in detail in our previous publications (Djeniže et al. 1992, 2002; Srećković et al. 2001a,b). Thus, only a few details will be given here. A discharge was made of Pyrex glass with an inner diameter of $5 \mathrm{~mm}$ providing an effective plasma length of $6.3 \mathrm{~cm}$. The tube was sealed by quartz windows. The working gas was $\mathrm{SF}_{6}$ at $130 \mathrm{~Pa}$ filling pressure in a flowing regime $(10 \mathrm{ml} / \mathrm{min})$. The chosen flux and pressure provide minimal self-absorption of the investigated spectral lines. Spectroscopic observations of isolated spectral lines were made end-on along the axis of 


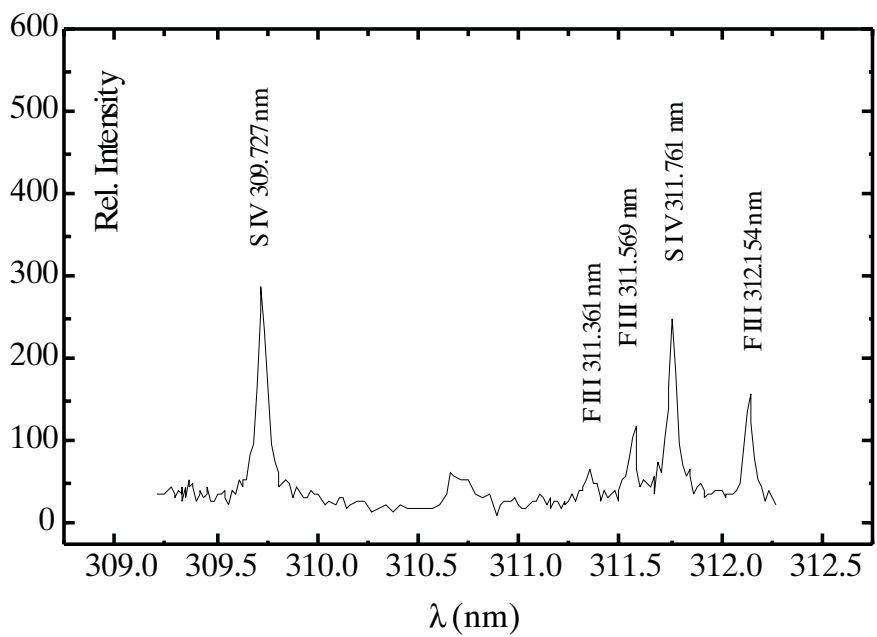

Fig. 1. Recorded spectrum with researched S IV spectral lines in the 3 th $\mu$ s after the beginning of the discharge.

the discharge tube. A capacitor of $14 \mu \mathrm{F}$ was charged up to $3.2 \mathrm{kV}$. The line profiles were recorded using a stepby-step technique with a photomultiplier (EMI 9789 QB) and a grating spectrograph (Zeiss PGS-2, reciprocal linear dispersion $0.73 \mathrm{~nm} / \mathrm{mm}$ in the first order) system. The system was calibrated by using the EOA-101 (halogen) standard lamp. The instrumental FWHM of $0.008 \mathrm{~nm}$ was determined by narrow spectral lines emitted from the hollow cathode discharge. The spectrograph exit slit $(10 \mu \mathrm{m})$ with the calibrated photomultiplier was micrometrically traversed along the spectral plane in small wavelength steps $(0.0073 \mathrm{~nm})$. The photomultiplier signal was digitized and averaged (five shots at each position) using an oscilloscope, interfaced to a computer. As an example, a recorded spectrum is presented in Fig. 1. The total line intensity $(I)$ corresponds to the area under the line profile.

Plasma reproducibility has been monitored by the F II and S III spectral lines and, also, by the discharge current using the Rogowski coil signal (the plasma reproducibility is $95 \%$ ). From the Rogowski coil signal we have found: discharge period $(33 \mu \mathrm{s})$, decrement (3.15), thermal resistance $(0.24 \Omega)$, self-inductance $(1.74 \mu \mathrm{H})$, discharge current maximum $(8.1 \mathrm{kA})$ and current rise time rate $(1.84 \times$ $\left.10^{9} \mathrm{~A} / \mathrm{s}\right)$.

The plasma parameters were determined using standard diagnostic methods (Rompe \& Steenbeck 1967). Thus, the electron temperature was determined from the Boltzmann plot of six F II lines within an energy interval of $6.46 \mathrm{eV}$ for corresponding upper levels $\left(E_{\mathrm{u}}\right)$ with an estimated error within $\pm 7 \%$, assuming the existence of LTE, according to the criterion from Griem (1974) and Rompe \& Steenbeck (1967). The Boltzmann plot, as an example, obtained at the 10th $\mu$ s after the beginning of the discharge is presented in Fig. 2.

The necessary atomic data have been taken from the available literature (Wiese et al. 1969; NIST 2002). The behaviour of the electron temperature decay is presented in Fig. 3. The electron density decay has been measured

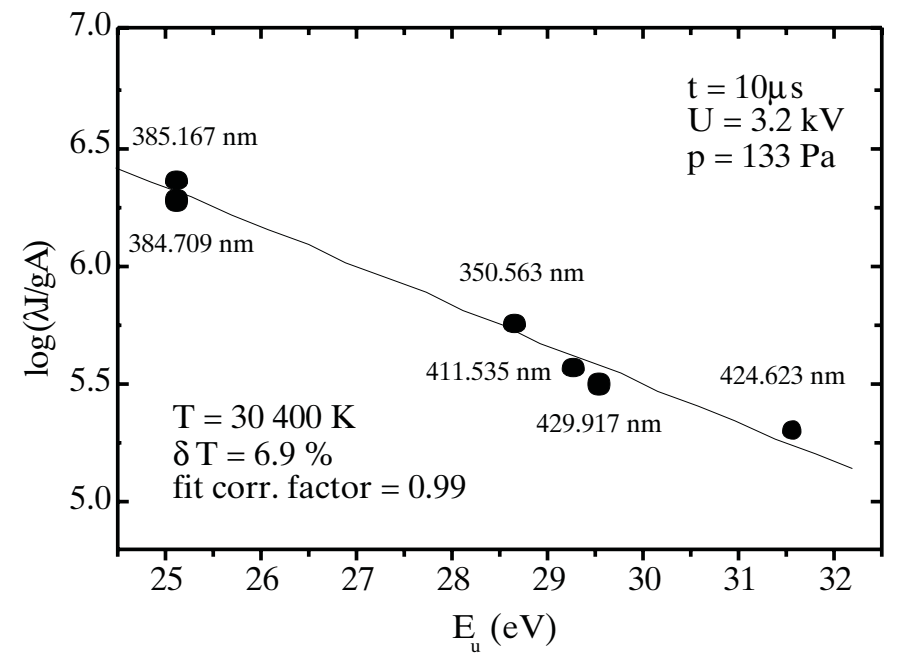

Fig. 2. Boltzmann plot on the basis of six F II spectral line relative intensities at the 10 th $\mu$ s after the beginning of the discharge.

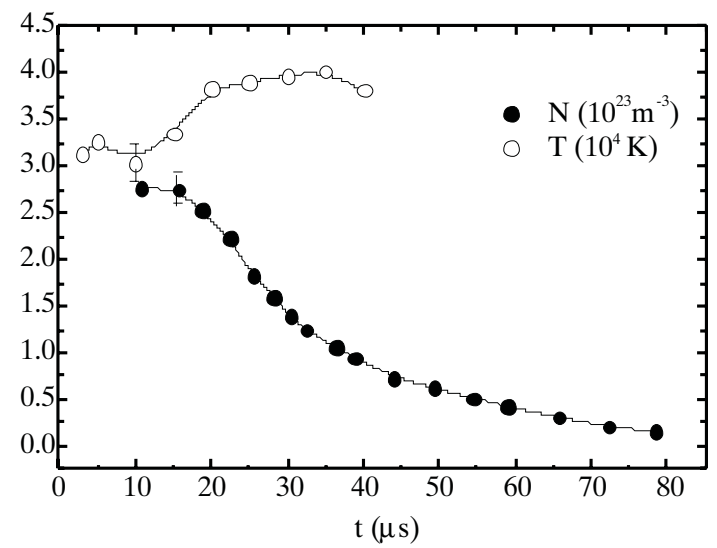

Fig. 3. Temporal evolutions of the electron temperature $(T)$ and electron density $(N)$.

using a well-known single laser interferometry technique (Ashby et al. 1965) for the $632.8 \mathrm{~nm} \mathrm{He}-\mathrm{Ne}$ laser wavelength with an estimated error of $\pm 6 \%$. The electron density decay is also presented in Fig. 3.

\section{Stark widths and shifts measurements}

The measured profiles were of the Voigt type due to the convolutions of the Lorentzian Stark and Gaussian profiles caused by Doppler and instrumental broadening. For the electron density and temperature presented in our experiment, the Lorentzian fraction was dominant. Van der Waals (Griem 1974) and resonance (Griem 1974) broadening were estimated to be smaller by more than one order of magnitude in comparison to Stark, Doppler and instrumental broadening. The standard deconvolution procedure (Davies \& Vaughan 1963) has been computed using the least square algorithm. The Stark widths have been measured with $\pm 12 \%$ error at a given $N$ and $T$. Great care has been taken to minimize the influence of selfabsorption on the Stark width determination. The opacity 


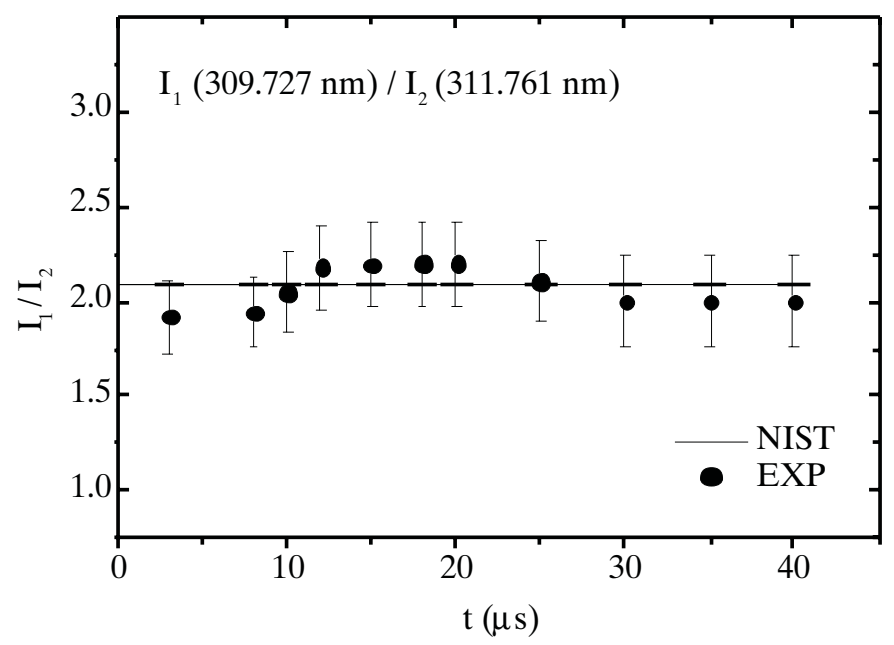

Fig. 4. Relative line intensity ratios $\left(I_{1} / I_{2}\right)$ during the plasma decay. $\bullet$, our experimental values with $\pm 10 \%$ accuracy. NIST, theoretical ratio obtained using existing transition probability values from NIST (2002).

has been checked by measuring relative line intensity ratios within the investigated multiplet during the plasma decay. The obtained values have been compared to the calculated ratios of the products of the spontaneous emission probabilities $(A)$ and the corresponding statistical weights $(g)$ of the upper levels of the lines. The necessary atomic data have been taken from NIST (2002). It turns out that the experimental relative line intensity ratios are constant during the whole plasma decay period (within $\pm 7 \%$ ), proving the absence of self-absorption (see Fig. 4.).

On the other hand, our experimental relative line intensity ratio $\left(I_{1} / I_{2}\right)$ agrees well (within $1 \%$ on average) with theoretical (NIST) values, during the whole plasma decay period. The theoretical ratio $\left(A_{309} / A_{311}\right)$ is $1.04=2.6 / 2.5$ (NIST 2002). Our obtained ratio is $1.03 \pm 17 \%$.

The Stark shifts have been measured by monitoring the line center position during the whole plasma decay period (Djeniže et al. 2002; and references therein). We have made corrections necessary to eliminate the influence of variations in electron temperature during plasma decay (Popović et al. 1992). The Stark shift data have been determined with a $\pm 0.8 \mathrm{pm}$ error at a given $N$ and $T$.

\section{Results and discussion}

Our measured Stark FWHM $\left(W_{\mathrm{m}}\right)$ and shift $\left(d_{\mathrm{m}}\right)$ values at given electron temperatures $(T)$ and densities $(N)$ are given in Table 1.

In order to compare the measured and calculated Stark FWHM and shift values, we have presented in Fig. 5 a single existing experimental data set including our results, together with relevant theoretical predictions.

The first S IV $W$ values have been calculated on the basis of various approximations initiated by Griem (1968, 1974), Hey \& Breger (1980) and Dimitrijević \& Konjević (1981). Thus, SE and MSE denote the results of semi-empirical (Griem 1968) and modified semi-empirical
Table 1. Measured Stark FWHM ( $W_{\mathrm{m}}$ in pm) and shift $\left(d_{\mathrm{m}}\right.$ in $\left.\mathrm{pm}\right)$ values for the S IV spectral lines at observed electron temperatures $\left(T\right.$ in $\left.10^{4} \mathrm{~K}\right)$ and densities $\left(N\right.$ in $\left.10^{23} \mathrm{~m}^{-3}\right)$. Positive shift is toward the red. Atomic data are taken from NIST (2002).

\begin{tabular}{cccccc}
\hline \hline Transition & $\lambda(\mathrm{nm})$ & $T$ & $N$ & $W_{\mathrm{m}}$ & $d_{\mathrm{m}}$ \\
\hline $4 \mathrm{~s}{ }^{2} \mathrm{~S}_{1 / 2}-4 \mathrm{p}{ }^{2} \mathrm{P}_{3 / 2}^{0}$ & 309.7273 & 3.04 & 2.75 & $63.8 \pm 12 \%$ & - \\
& & 3.36 & 2.80 & $60.2 \pm 12 \%$ & $3.9 \pm 0.8$ \\
$4 \mathrm{~s}^{2} \mathrm{~S}_{1 / 2}-4 \mathrm{p}{ }^{2} \mathrm{P}_{1 / 2}^{0}$ & 311.7615 & 3.04 & 2.75 & $58.0 \pm 12 \%$ & - \\
& & 3.36 & 2.80 & $53.2 \pm 12 \%$ & $0.0 \pm 0.8$ \\
\hline
\end{tabular}

predictions using Eqs. (4), (5) and Eqs. (7)-(10), respectively from Dimitrijević \& Konjević (1981). G and GM denote $W$ values obtained on the basis of the simplified semiclassical method (Griem 1974) calculated by Dimitrijević \& Konjević (1981). Hey \& Breger (1980) calculated $W$ values using semiclassical impact approximation only at the $T$ value obtained in the experiment presented by Platiša et al. (1979). SCPF denotes the results of the semiclassical perturbation formalism presented by Dimitrijević et al. (1996) using approximations explained in Sahal-Bréchot (1969a,b).

On the basis of Table 1 and Fig. 5 one can conclude that our measured $\left(W_{\mathrm{m}}\right)$ Stark FWHM values are in satisfactory agreement (within $15 \%$ on average) with predictions of SCPF and G approximation based on the semiclassical approaches. It should be pointed out that the mentioned calculations contain only the electron contribution to the Stark FWHM (and shift). Inclusion of the ion (F II, F III, S II, S III, S IV, ...) contribution to the total theoretical $\mathrm{W}$ values imply the knowledge of the necessary ion broadening $\left(W_{i}\right)$ parameters which have not been known so far. The inclusion of the $W_{i}$ could increase the total $W$ value (for a few percent) making the agreement between our $W_{\mathrm{m}}$ values and $W_{\mathrm{SCPF}}$ even better. Our $W_{\mathrm{m}}$ values lie approximately $100 \%$ above the earlier measured value (Platiša et al. 1979) and above SE, MSE and GM approximations.

We have obtained Stark shifts $\left(d_{\mathrm{m}}\right)$ that are equal to zero or have very small positive value. The single theoretical values $\left(d_{\mathrm{SCPF}}\right)$ are also very small, but have a negative sign for $T$ higher than $20000 \mathrm{~K}$. Taking into account the difficulties of the theoretical calculations of the Stark shift values connected to the knowledge of the necessary atomic data (Djeniže et al. 1993) the disagreement between very small experimental and calculated values can be considered as tolerable.

It turns out that the calculated $d$ values are approximately constant $(-0.5 \mathrm{pm})$ over a wide range of the electron temperatures from $20000 \mathrm{~K}$ to $200000 \mathrm{~K}$.

\section{Conclusion}

Our measured Stark width and shift values agree with the results based on the semiclassical theory within 


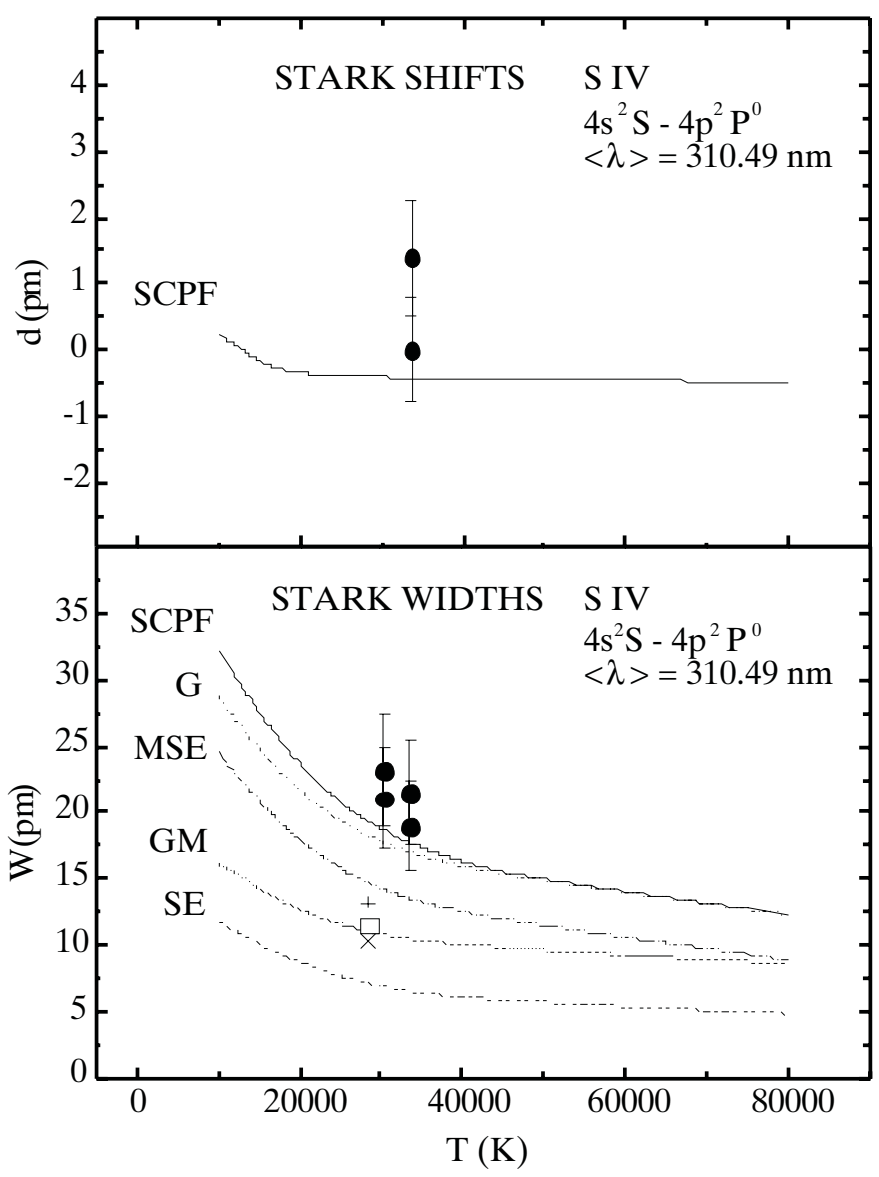

Fig. 5. Stark FWHM ( $W$ in pm) and shift ( $d$ in pm) dependence on the electron temperature $(T)$ for the investigated S IV spectral lines at $10^{23} \mathrm{~m}^{-3}$ electron density. •, our experimental results and those of other authors: $\square$, Platiša et al. (1979). SCPF, calculations by the use of the semiclassical perturbation formalism (Dimitrijević et al. 1996). SE, MSE, G and GM denotes theoretical $W$ values (see text). + and $\times$, calculations by Hey \& Breger (1980). Theoretical predictions contain only the electron contribution to the $W$ and $d$ values. The error bars include the uncertainties of the width and electron density measurements $( \pm 18 \%)$. In case of the Stark shifts the error bar represents $\pm 0.8 \mathrm{pm}$ uncertainties. $\langle\lambda\rangle$ is the mean wavelength in the multiplet.

the accuracy of the measurement and uncertainties in the theoretical calculations confirming the reliability of this approximation in the case of the $4 \mathrm{~s}^{2} \mathrm{~S}-4 \mathrm{p}^{2} \mathrm{P}^{0}$ transition in the S IV spectrum. We expect that the inclusion of the ion contribution to the total $W$ and $d$ values could improve the existing agreement. However, this step will be carried out in future theoretical investigations.

Acknowledgements. This work is a part of the project "Determination of the atomic parameters on the basis of the spectral line profiles" supported in part by the Ministry of Science, Technologies and Development of the Republic of Serbia. S.Djeniže is grateful to the Foundation "Arany János Közalapitvány" Budapest, Hungary.

\section{References}

Ashby, D. E. T. F., Jephcott, D. F., Malein, A., \& Raynor, F. A. 1965, Appl. Phys., 36, 29

Bianchi, L., Hutchings, J. B., Fullerton, A. W., et al. 2000, ApJ, 538, L57

Davies, J. I., \& Vaughan, J. M. 1963, ApJ, 137, 1302

Dimitrijević, M. S., \& Konjević, N. 1981, in Spectral Line Shapes vol. 1, ed. B. Wende (W. de Gruyter \& Co. New York), 211

Dimitrijević, M. S., Djeniže, S., Srećković, A., \& Platiša, M. 1996, Phys. Scr., 53, 545

Djeniže, S., Srećković, A., \& Labat, J. 1992, A\&A, 253, 632

Djeniže, S., Popović, L. Č., Labat, J., Srećković, A., \& Platiša, M. 1993, Contrib. Plasma Phys., 33, 193

Djeniže, S., Milosavljević, V., \& Dimitrijević, M. S. 2002, A\&A, 382,359

Fullerton, A. W., Crowther, P. A., De Marco, et al. 2000, ApJ, 538, L43

Griem, H. R. 1968, Phys. Rev., 165, 258

Griem, H. R. 1974, Spectral Line Broadening by Plasmas (Academic Press, New York)

Hey, J. D., \& Breger, P. 1980, JQSRT, 24, 427

Lesage, A. 1994, in the Proc. of the XXIInd General Assembly of the International Astronomical Union, le Haie

Lesage, A., \& Fuhr, J. R. 1999, Bibliography of Atomic Line Shapes and Shifts (April 1992 through June 1999), Observatoire de Paris

Martin-Hernández, N. L., et al. 2002, A\&A, 381, 606

Mauche, C. W. 1999, ApJ, 520, 822

NIST 2002, Atomic Spectra Database Lines Data, http://www.physics.nist.gov

Okamoto, Y. K., Kataza, H., Yamashita, T., Miyata, T., \& Onaka, T. 2001, ApJ, 553, 254

Platiša, M., Popović, M., Dimitrijević, M. S., \& Konjević, N. 1979, JQSRT, 22, 333

Popović, L. Č., Srećković, A., \& Djeniže, S. 1992, Proc. of the 11th ICSLS, A25, Carry le Rouet, France

Rompe, R., \& Steenbeck, M. 1967, Ergebnisse der Plasmaphysik und der Gaselektronik, Band 1 (Berlin: Akademie Verlag)

Sahal-Bréchot, S. 1969a, A\&A, 1, 91

Sahal-Bréchot, S. 1969b, A\&A, 2, 322

Srećković, A., Dimitrijević, M. S., \& Djeniže, S. 2001a, A\&A, 371,354

Srećković, A., Drinčić, V., Bukvić, S., \& Djeniže, S. 2001b, Phys. Scr., 63, 306

Wiese, W. L., Smith, M. W., \& Miles, B. M. 1969, Atomic Transition Probabilities, NSRDS-NBS 22, vol. 2 (DC: US Govt. Print. Office, Washington)

Zeippen, C. J. 1995, Phys. Scr., 58, 43 